\title{
READING THE RESEARCH: PUBLICATIONS ON VERNACULAR ARCHITECTURE
}

\author{
GULIZ OZORHON \& ILKER FATIH OZORHON \\ Department of Architecture, Ozyegin University, Turkey
}

\begin{abstract}
The aim of this study is to analyze the general profile of articles written on the subject of "vernacular architecture" (VA). The study integrates articles posted on the Web of Science database. In the first part of this study, all English language articles scripted between 2000 and 2018 and in the second part, articles listed under architecture category have been examined. Articles were analyzed based on their publication year, journals, categories, keywords and method and obtained data were analyzed via content-analysis method. Research findings manifest that VA is interlinked with a wide array of disciplines ranging from architecture-engineering sciences to art, archeology and geography. Once all of these categories are examined, it can be argued that, in general, local architecture is analyzed by associating it with environmental issues and building-physics subjects. Researchers claim that analyzing local production techniques and, based on these techniques, developing local, effective strategies is a salient research method. In the architecture category, the most widely-analyzed scale was detected as region scale; the most discussed location was Iran in the global scope. One of the featured titles in these studies is on the subject of thermal comfort. Another common subject in these articles is detected to be sustainability and matters related to sustainability. Aside from the subjects and concepts examined in these studies, another issue is the motives with which analyzed subjects were associated. Here, compiled data reveal that studies related to VA offer three key motives. The first one is protecting, the second one is learning and the third one is developing.
\end{abstract}

Keywords: vernacular architecture, WOS, architecture.

\section{INTRODUCTION}

We believe that architecture knowledge from the past includes in itself a long list of insights that should be transferred to present and future age. It is necessary that vernacular architecture knowledge that was repeatedly tested, collected and transferred across generations should be investigated through different analyses and evaluations to make it visible through publishing so that it would be a guideline for architecture production. Noting that we are in a critical age especially in terms of questioning our relationship with nature, the significance of vernacular architecture knowledge tightly connected with nature becomes more obvious (Ozorhon et al. [1]). Vernacular buildings' traditions are not remnants of an underdeveloped or romantic past but are important and relevant to many cultures and peoples in the world, past, present and future (Asquith and Vellinga, [2]). Traditional principles have evolved over a long period of time in virtually all countries of the world. People have developed building techniques excellently adapted to the building materials available and local conditions such as the climate (Oliver [3]). In architecture domain, "vernacular architecture" has always been a valued subject of research for scholars and scientific studies on this subject have constituted a vast area in relevant literature. However, in this knowledge unity, it is greatly vital to analyze and interpret these studies holistically aside from examining the unique arguments of each study. This paper aims to collectively analyze scientific studies on "vernacular architecture" (VA). Studies on this subject can basically be categorized under two parts. The first one is documenting a location (context)/settlement with detecting by various methods and architectural representation tools. These studies also hold value as they offer some background for prospective studies. Some of the studies on vernacular architecture also aim 
to transfer vernacular architecture knowledge to modern designs. In some instances, these studies can achieve mentioned flow of knowledge by interlinking with modern parameters - sustainability, ecologic design, passive environmental control system etc. These studies are vitally important for the transfer and sustainability of architecture culture and experience. (Ozorhon and Ozorhon [4]).

\subsection{Methodology}

Studies on a specific branch accumulate in the course of time and create relevant literature. It is vital that academics from a discipline could determine tendencies of studies in this discipline and common characteristics. Based on this belief this paper tracks VA subject in examined articles and aims to view all studies from past to now on a common ground. In that sense key questions of this paper are such:

- In the articles which concepts laid the ground for VA analysis?

- Which themes laid the ground for VA analysis?

- How did these concepts and themes evolve from the past to present day?

Sampling domain of the study was limited with Web of Science (WOS) database and in order to use within the context of this study, a research model/strategy formed with the unique dynamics of VA subject has been developed. In Fig. 1, the research strategy is exhibited as a cluster. As seen, research is formed with two layers and at the end of this research, data collected from both layers are collectively interpreted. The research model necessitated using different methods in order to analyze a variety of dynamics interlinked with VA. Thus, in order to read the publications holistically methods that fit with the nature of data were utilized and research's quantitative and qualitative results were stated by supporting with graphics and cluster. In the 1st layer of research model, VA discourse was examined in all articles

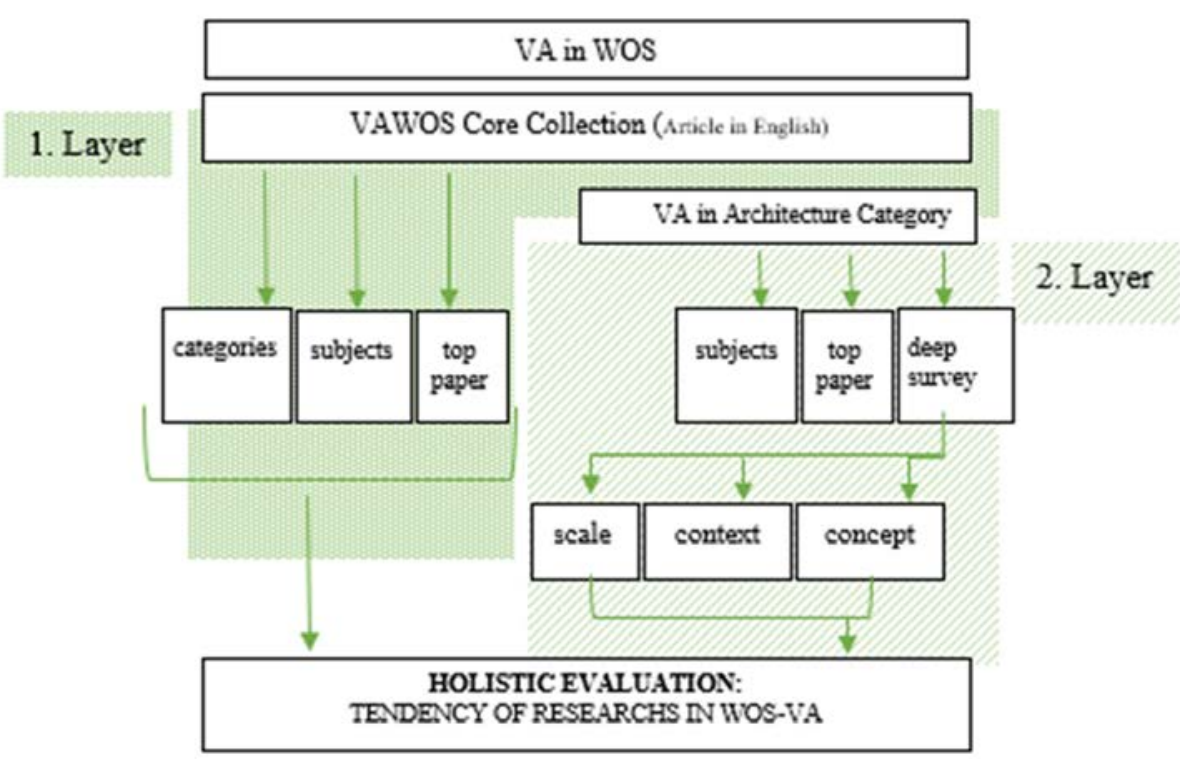

Figure 1: Strategy of the research. 
published under WOS-subject while in the 2nd layer the analysis was narrowed down to fit the architecture category. In this system it was aimed to analyze it generically in the entire domain in the first stage of research while in the second stage VA was aimed to be examined in depth in particularly architecture domain. Thus, sub parameters of 1 st Layer are: categories, subjects and top articles but sub parameters of 2nd Layer are detected as subjects, top articles and deep survey. In the research, data analysis was based on employing SciMAT (Science Mapping Analysis software Tool) (Cobo [5]) software and concept maps.

\subsection{1 st Layer}

In the 1st Layer of research VA discourse was scanned through WOS-subject. At the end of this scan a sum of 542 articles written in English language were accessed for the period between 1979 and 2018. A second-filtering process was applied on the articles. After filtering process publications from 1979-2000 and failing to provide significant data for quantity and quality were excluded from the scope of research. Finally, as the analysis unit of the first layer of research, 482 articles dated between 2000 and 2018 were detected in the core collection of Web of Science.

\section{RESEARCH FINDINGS}

As seen for the period of 2000-2018, publications on VA gained acceleration particularly after 2008 (Table 1/Fig. 2). These publications, based on the categories they were listed on WOS database, were independently scanned with respect to the journals they belonged to and reference statistics. Accordingly collected findings are as listed below.

- Based on the domains in which articles were interlinked with WOS the first rank belonged to architecture (173) ensued by Construction Building Technology (89), Engineering Civil (60), Environmental Studies (49) and Urban Studies (39) as the top five of the category. It is seen that VA was a research subject not only in architecture but also in engineering disciplines of technology.

- Top five journals that released VA related studies are: Building and Environment (26), Energy and Buildings (18), Open House International (18), Architectural Science Review (11), Vernacular Architecture (11). In Building and Environment journal scope most common topics of analysis were respectively "building science, urban physics, and human interaction with the indoor and outdoor built environment". It is worth noticing that journals predominantly focused on building physics subject. This can be interpreted as an indication that VA subject was, at most, analyzed by building-physics researchers.

Table 1: For the period of 2000-2018, VA-related articles issued on WOS.

\begin{tabular}{ccc}
\hline $\mathbf{P}$ & Years & A \\
\hline $\mathbf{1}$ & $2000-2001$ & 13 \\
\hline $\mathbf{2}$ & $2002-2003$ & 13 \\
\hline $\mathbf{3}$ & $2004-2005$ & 12 \\
\hline $\mathbf{4}$ & $2006-2007$ & 16 \\
\hline $\mathbf{5}$ & $2008-2009$ & 28 \\
\hline $\mathbf{6}$ & $2010-2011$ & 52 \\
\hline $\mathbf{7}$ & $2012-2013$ & 42 \\
\hline $\mathbf{8}$ & $2014-2015$ & 85 \\
\hline $\mathbf{9}$ & $2016-2017$ & 152 \\
\hline $\mathbf{1 0}$ & 2018 & 69 \\
\hline
\end{tabular}




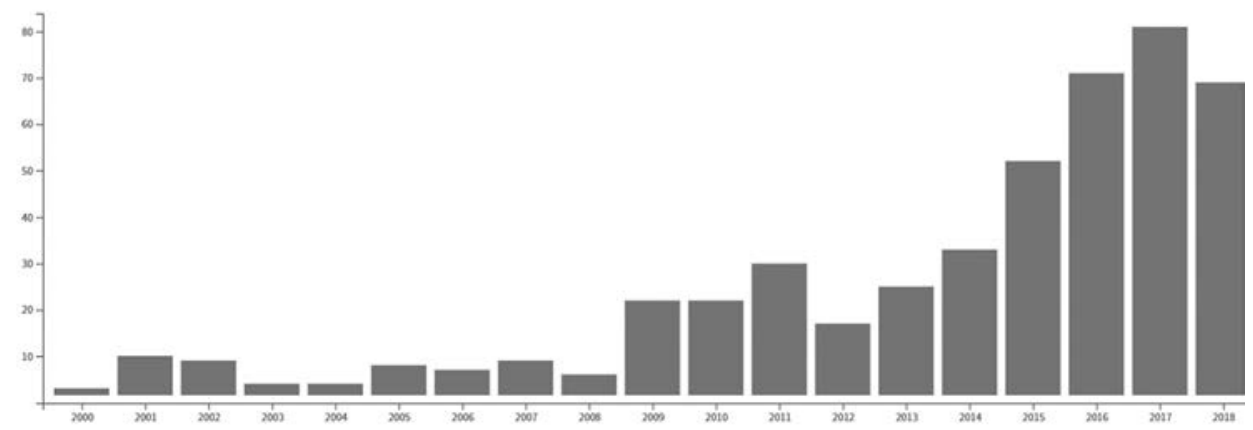

Figure 2: For the period of 2000-2018, "vernacular architecture" related publications issued on WOS.

- In order to elaborately analyze 482 articles written between 2000-2018, SciMAT software was harnessed. In the software period of 2000-2018 was analyzed as two-year periods and obtained diagrams were combined (Table 2). According to the results of analysis, during these two-year periods most popular themes were; environment, buildings, city, wind-catcher, strategies, residential buildings, modern building and vernacular-house.

Among 482 publications issued on WOS core collection, top five articles most frequently referred are as seen in Table 3.

Ratti et al. [6] article titled as "Building form and environmental performance: archetypes, analysis and an arid climate" was the most widely-referred article. The most referred article questioned the influential articles (March and Trace [7]) of the 1960s and asked the optimalland form for buildings and investigated the best form in arid climate for the land settlement of buildings.

\subsection{2nd Layer}

For the 2nd layer of this study, among 482 articles, the Architecture category was filtered and in Web of Science core collection-Architecture category; 173 articles dated to the period of 2000-2018 were named as the analysis unit of 2nd layer of the research.

As seen for the period of 2000-2018, VA-related publications in Architecture category gained acceleration particularly after 2009 (Table 4/Fig. 3). In these articles the most frequently referred five sources are as seen in Table 5.

Among these 173 articles in the Architecture category of WOS core collection the most frequently-referred five studies are seen in Table 6.

Highest referenced article is Calautit et al. [8] work "A numerical investigation into the feasibility of integrating green building technologies into row houses in the Middle East". The article draws a comparison between wind towers integrated as the green-building technology into Middle-East row house model and traditional tools. 
Table 2: Based on SciMAT software, 10-year period and clusters in these periods.

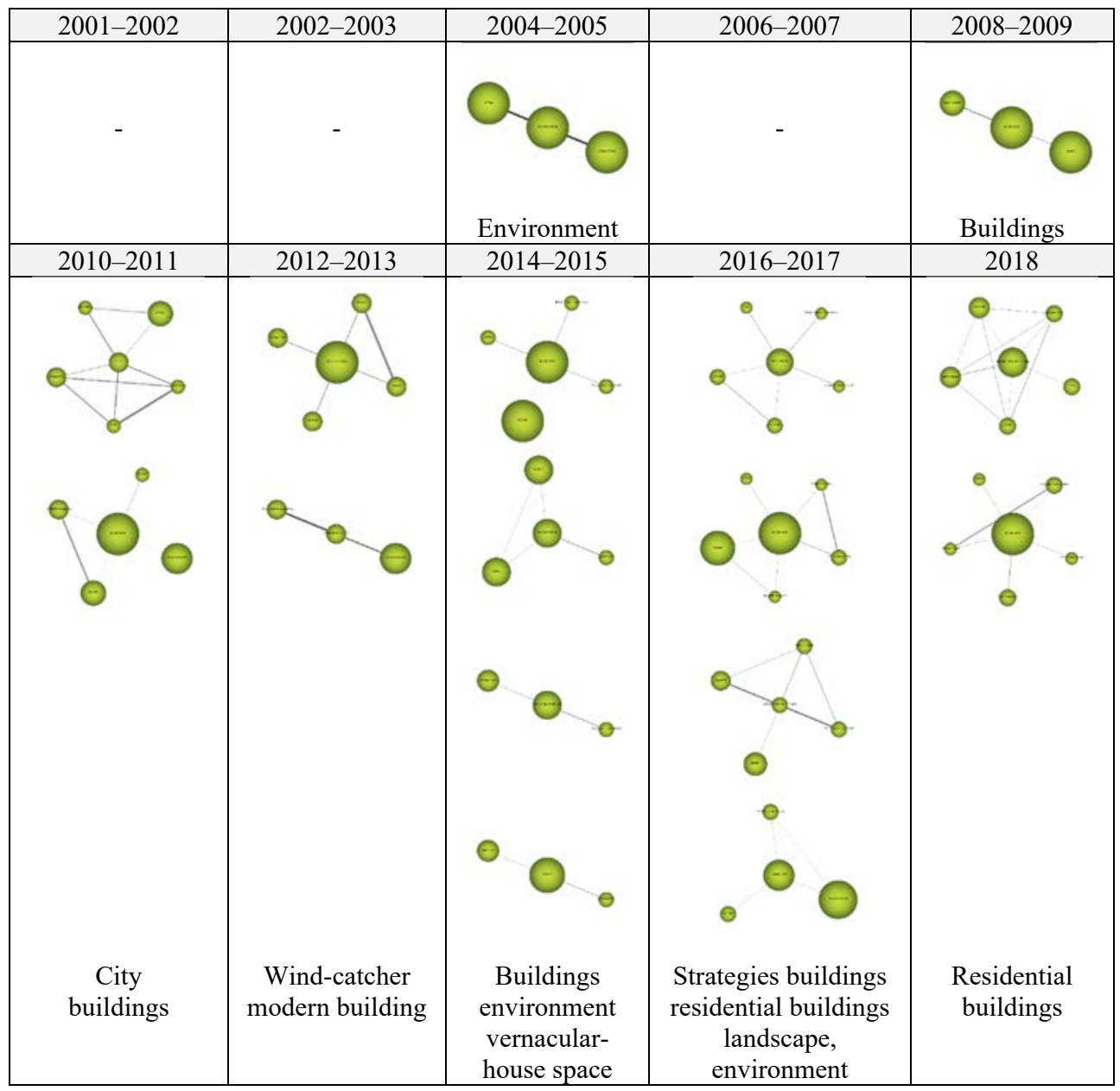

Table 3: Top-5 referred articles related to VA.

\begin{tabular}{llcc}
\hline Article & Authors & Year & C \\
\hline $\begin{array}{l}\text { Building form and environmental } \\
\text { performance: archetypes, analysis and } \\
\text { an arid climate }\end{array}$ & $\begin{array}{l}\text { Ratti, C., Raydan, D., Steemers, } \\
\text { K. }\end{array}$ & 2003 & 130 \\
\hline $\begin{array}{l}\text { Enhancing visual preference of } \\
\text { ecological rehabilitation sites }\end{array}$ & Hands, D.E., Brown, R.D. & 2002 & 86 \\
\hline $\begin{array}{l}\text { Outdoor thermal comfort in the old } \\
\text { desert city of Beni-Isguen, Algeria }\end{array}$ & $\begin{array}{l}\text { Ali-Toudert, F., Djenane, M., } \\
\text { Bensalem, R., Mayer, H. }\end{array}$ & 2005 & 74 \\
\hline $\begin{array}{l}\text { Ancient vernacular architecture: } \\
\text { characteristics categorization and } \\
\text { energy performance evaluation }\end{array}$ & Zhai, Z.Q., Previtali, J.M. & 2010 & 73 \\
\hline $\begin{array}{l}\text { Thinking cities through elsewhere: } \\
\begin{array}{l}\text { Comparative tactics for a more global } \\
\text { urban studies }\end{array}\end{array}$ & Robinson, J. & 2016 & 66 \\
\hline
\end{tabular}


Table 4: VA-related publications issued on WOS Architecture category between 2000-2018.

\begin{tabular}{ccc}
\hline $\mathbf{P}$ & Years & A \\
\hline $\mathbf{1}$ & $2000-2001$ & 2 \\
\hline $\mathbf{2}$ & $2002-2003$ & 2 \\
\hline $\mathbf{3}$ & $2004-2005$ & - \\
\hline $\mathbf{4}$ & $2006-2007$ & 5 \\
\hline $\mathbf{5}$ & $2008-2009$ & 15 \\
\hline $\mathbf{6}$ & $2010-2011$ & 16 \\
\hline $\mathbf{7}$ & $2012-2013$ & 18 \\
\hline $\mathbf{8}$ & $2014-2015$ & 31 \\
\hline $\mathbf{9}$ & $2016-2017$ & 58 \\
\hline $\mathbf{1 0}$ & 2018 & 24 \\
\hline
\end{tabular}

173

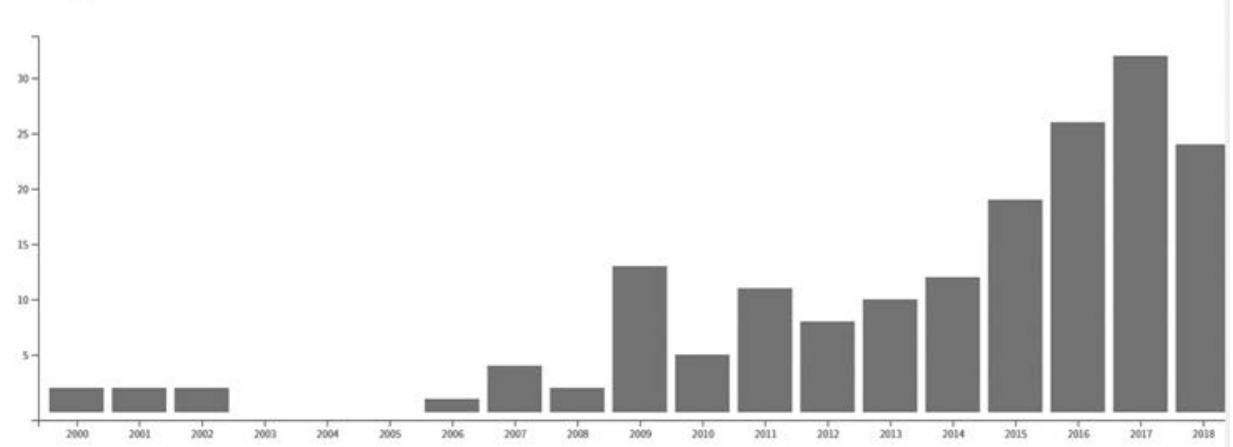

Figure 3: "Vernacular architecture" related publications issued on WOS Architecture category between 2000-2018.

Table 5: The most frequently-referred studies.

\begin{tabular}{lll}
\hline Author & Year & Name \\
\hline Rapoport A. & 1969 & HOUSE FORM CULTURE \\
\hline Rudofsky B. & 1964 & ARCHITECTURE ARCHITE. \\
\hline Oliver P. & 2006 & MEET NEEDS CUL. \\
\hline Oliver P. & 1997 & ENCY VERNACULAR ARCH. \\
\hline Oliver P. & 2003 & DWELLINGS VERNACULAR \\
\hline * listed on the basis of reference statistics. & &
\end{tabular}

* listed on the basis of reference statistics. 
Table 6: The most frequently referred five articles related to VA in the Architecture category of WOS.

\begin{tabular}{|c|c|c|c|}
\hline Article & Authors & Year & $\mathrm{C}$ \\
\hline $\begin{array}{l}\text { A numerical investigation into the } \\
\text { feasibility of integrating green building } \\
\text { technologies into row houses in the Middle } \\
\text { East }\end{array}$ & $\begin{array}{l}\text { Calautit, J.K., Hughes, B., } \\
\text { Ghani, S.A. }\end{array}$ & 2013 & 28 \\
\hline $\begin{array}{l}\text { Hassan Fathy revisited - Postwar } \\
\text { discourses on science, development, and } \\
\text { vernacular architecture }\end{array}$ & Pyla, P.I. & 2007 & 15 \\
\hline $\begin{array}{l}\text { Modernity in tradition: Reflections on } \\
\text { building design and technology in the } \\
\text { Asian vernacular }\end{array}$ & Rashid, M., Ara, D.R. & 2015 & 13 \\
\hline $\begin{array}{l}\text { Thermal and comfort conditions in a semi- } \\
\text { closed rear wooded garden and its } \\
\text { adjacent semi-open spaces in a } \\
\text { Mediterranean climate (Athens) during } \\
\text { summer }\end{array}$ & Tsiros, I.X., Hoffman, M.E. & 2014 & 13 \\
\hline $\begin{array}{l}\text { Field Investigation of Indoor Thermal } \\
\text { Environments in Traditional Chinese Shop } \\
\text { houses with Courtyards in Malacca }\end{array}$ & $\begin{array}{l}\text { Kubota, T., Toe, D.H.C., } \\
\text { Ossen, D.R. }\end{array}$ & 2014 & 10 \\
\hline
\end{tabular}

In order to conduct a more detailed observation on the 173 articles in WOS core collection's Architecture category and with Table 7 displaying the relevant categories, collected data were combined as an integrated table, Table 8, and in this table 173 articles were examined under three single thematic frameworks; titles of scale, context and concept. Thus, the most dominant scales, locations and concepts in the articles were aimed to be observed. Accordingly, most-frequently analyzed scales were Region, Landscape, Urban, and House. In the articles lead locations were Iran, America and England.

Leading concepts in these articles were reported to be thermal, sustainability, sustainable technology and culture.

\section{HOLISTIC EVALUATION}

As Asquith [9] emphasized, vernacular architecture is a subject without a discipline. Those that study it come from many disciplines from anthropology, sociology and behavioral studies to human geography, history and architecture itself (Asquith [9]). Research findings also manifest that VA is interlinked with a wide array of disciplines ranging from architecture-engineering sciences to art, archeology and geography. Architecture is the discipline in which VA has been most widely discussed. In architecture domain, VA belongs to a vital research scope and for the last decade in particular, there has been a significant rise in relevant studies which indicates that VA is still deemed to be a modern scope of study for

Table 7: Categories in the table of the deep research.

\begin{tabular}{|c|c|c|c|c|c|c|c|}
\hline code & year & journal & Name & *scale & *context & *concept & keywords \\
\hline $\begin{array}{l}\text { papers } \\
\text { code in } \\
\text { the } \\
\text { research }\end{array}$ & $\begin{array}{c}\text { year } \\
\text { of } \\
\text { public. }\end{array}$ & $\begin{array}{l}\text { published } \\
\text { journal }\end{array}$ & $\begin{array}{c}\text { names } \\
\text { of } \\
\text { article }\end{array}$ & $\begin{array}{l}\text { architectural } \\
\text { scale }\end{array}$ & $\begin{array}{c}\text { place } \\
\text { examined }\end{array}$ & $\begin{array}{c}\text { mentioned } \\
\text { concepts }\end{array}$ & $\begin{array}{c}\text { keywords } \\
\text { of the } \\
\text { article }\end{array}$ \\
\hline
\end{tabular}


Table 8: Scale, context and concepts.

scale

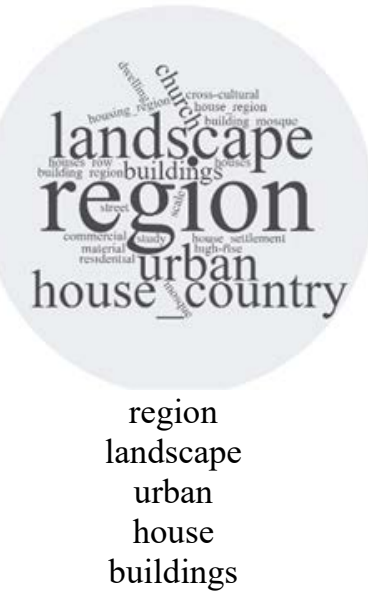

context

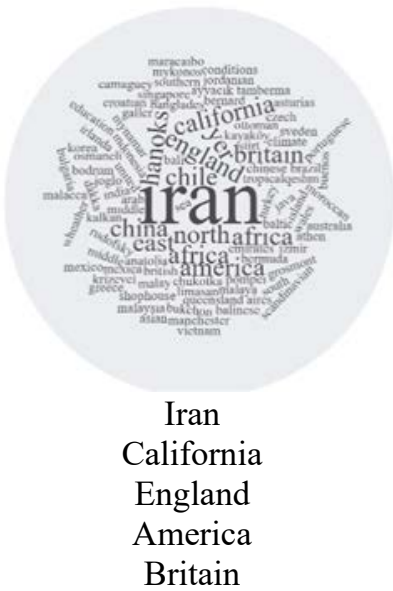

concepts

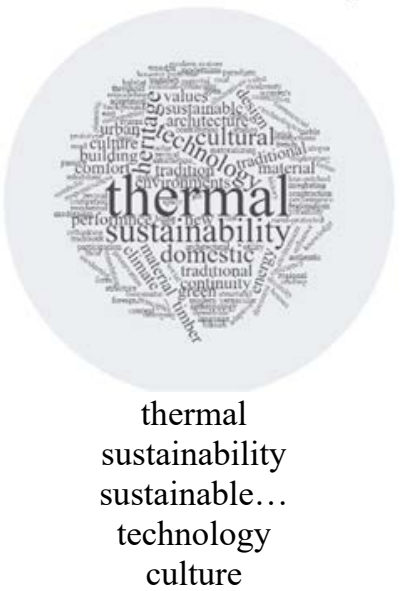

architecture researchers. However, as all the categories are examined it surfaces that basically the vernacular was analyzed through environmental issues and in relation with building physics. Researchers deem that analyzing vernacular production techniques and based on these techniques, developing local, effective strategies is an important research method.

Studies related with vernacular-architecture are noticeably diversified in terms of scale, context and concept perspectives. As the research scales in publications from architecture category prove, there is a vast profile ranging from housing scale to urban scale but the most-widely analyzed scale is region scale. In these studies, many parts of the world were examined and a large context from America to the Middle East was illustrated. However, the most common research topic was detected as Iran. A featured title in the studies was related with thermal comfort. One reason could be that in the analyses based on the quality of space, comfort condition of a space is one of the other factors. Another cause for featuring this title in the articles is that these conditions allow to conduct analyses based on tangible data that can be converted to numeric data.

Sustainability and sustainability-related subjects were also common points of discussion in the articles. The recent writings on vernacular architecture and sustainability constitute a vibrant and growing discourse that makes an important contribution to the field of vernacular architecture studies. As Oliver [10] stated, vernacular architecture is the time-honored, truly sustainable architecture that, in its multitudinous manifestations, has evolved over the centuries, changing or adapting when necessary to variable environments and the nature of family and social growth. It is essential to refer to vernacular knowledge in order to learn what is or what sustainability and sustainable architecture should be like (Ozorhon and Ozorhon [11]). Vernacular architectures are typical examples which show how local climate conditions, materials, techniques, building systems and living style, traditions and socioeconomic conditions shaped how people lived in the region (Sozen and Gedik [12]).

Aside from the subjects and concepts analyzed in the studies, another topic is about the motives that analyzed subjects are associated with. What are the motives of studies focusing on VA? At this stage, compiled data reveal that studies related with VA point to three key motives the first of which is protecting, second one is learning and third one is developing. A vast majority of these studies are linked with identification and protection. Another group 
is built upon learning from the ancient VA knowledge. Third theme that studies address to is developing. Studies in this theme aim to interpret vernacular knowledge together with modern knowledge and technology and develop new strategies based on this blend.

\section{CONCLUSION}

The main motivation of this paper is to explore how vernacular architecture is studied by architectural researchers. The study is based on the analysis of 482 articles on vernacular architecture published between 2000 and 2018 and scanned in WOS. When these articles are evaluated, it can be said that the number of publications focusing on the integration of vernacular architectural knowledge with contemporary knowledge and technology has increased especially in recent years. In the titles or key motivation of these studies "learning from" is a common discourse but future studies are responsible for moving these approaches one step ahead. By uniting learning from vernacular architecture with the knowledge on "location" and blending with technology they should develop innovative methods of which physical tests are conducted. These studies should be supported via interdisciplinary partnerships and their positive/negative results should be, with all their pros and cons, shared with research circles.

\section{REFERENCES}

[1] Ozorhon, G., Ozorhon, I.F. \& Hacihasanoğlu, O., Plus ten to architectural education (+10)201. Ege Mimarlı, 87, pp. 46-49, 2014.

[2] Asquith, L. \& Vellinga M., Introduction. Vernacular Architecture in the Twenty-First Centrury: Theory, Education and Practice, eds L. Asquith \& M. Vellinga, pp. 1-20, 2006.

[3] Oliver, P., Encyclopaedia of Vernacular Architecture of the World, Cambridge University Press: Cambridge, 1997.

[4] Ozorhon, G. \& Ozorhon, I.F., Learning from experience in architecture: Fathy, Correa, Cansever. International Review of Social Sciences and Humanities, 11(1), pp. 41-53, 2016.

[5] Cobo, M.J., López-Herrera, A.G., Herrera-Viedma, E. \& Herrera, F., Science mapping software tools: review, analysis, and cooperative study among tools. Journal of the American Society for Information Science and Technology, 62, pp. 1382-1402, 2011.

[6] Ratti, C., Raydan, D. \& Steemers, K., Building form and environmental performance: Archetypes, analysis and an arid climate. Energy and Buildings, 35, pp. 49-59, 2003.

[7] March, L. \& Trace, M., The Land-Use Performances of Selected Arrays of Built Forms, L.U.B.F.S. Working Paper No. 2, 1968.

[8] Calautit, J.K., Hughes, B.R. \& Ghani, S.A., A numerical investigation into the feasibility of integrating green building technologies into row houses in the Middle East. Architectural Science Review, 56(4), pp. 279-296, 2012.

[9] Asquith, L., Lessons from the vernacular integrated approaches and new methods for housing research. Vernacular Architecture in the Twenty-First Century Theory, Education and Practice, eds L. Asquith \& M. Vellinga, pp. 128-144, 2006.

[10] Oliver, P., Raising the roof. Vernacular Architecture in the Twenty-First Century Theory, Education and Practice, eds L. Asquith \& M. Vellinga, pp. 262-268, 2006.

[11] Ozorhon, G. \& Ozorhon, I.F., Learning from Mardin and Cumalıkızık: Turkish vernacular architecture in the context of sustainability: Mardin, Cumalıkızık. ArtsOpen Access Journal, 3(1), pp. 175-189, 2014.

[12] Sozen, M.S. \& Gedik, G.Z., Evaluation of traditional architecture in terms of building physics: Old Diyarbakir houses. Building and Environment, 42, pp. 1810-1816, 2007. 